\title{
A Contribution for a Pragmatics-Based Approach to Concurrent Engineering Implementation
}

\author{
Nenad Popovic ${ }^{1}$ - Goran D. Putnik ${ }^{2},{ }^{*}$ - Ondrej Jasko ${ }^{3}$ - Jovan Filipovic ${ }^{3}$ \\ 1 ABS Electro, Russia \\ ${ }^{2}$ University of Minho, Department of Production Engineering and Systems, Portugal \\ 3 University of Belgrade, Faculty of Organizational Sciences, Serbia
}

\begin{abstract}
The paper investigates how a pragmatics-based approach may influence Concurrent Engineering (CE) implementation projects. Pragmatics, a field of semiotics, is used as a perspective for analyzing, as an instrument for constructing manufacturing systems and, in this particular research, as an instrument for CE implementation projects. In particular, as a part of the CE implementation methodology, modeling and the effects of different interpretations (as pragmatics aspects) of the assessment of processes' simultaneity in a manufacturing organization are studied. The underlying thesis is that different interpretations significantly influence the perception of the organization's reality, which has an impact on the project's success. As a representation class, the so-called Simultaneity (Concurrency) Matrix (SCM) was used for simultaneity process assessment. The thesis is validated in two manufacturing companies. The results suggest that further improvements of the CE implementation methodologies, when using the pragmatics-based approach, lead to better quality of decisions and provide some assurance for the success of short-time and low-cost CE implementation projects.
\end{abstract}

Keywords: pragmatics, Concurrent Engineering, simultaneity assessment, Concurrent Engineering implementation, Simultaneity (Concurrency) Matrix (SCM)

\section{INTRODUCTION}

This paper investigates how a pragmatics-based approach may influence Concurrent Engineering (CE) implementation projects. Pragmatics, a field of semiotics, is used as a perspective for analyzing and constructing manufacturing systems, i.e. CE implementation projects. Predominantly, as a part of the $\mathrm{CE}$ implementation strategy, which also includes $\mathrm{CE}$ readiness assessment, modeling and effects of different interpretations of the assessment of processes simultaneity, as pragmatics aspects are studied. This paper follows the theoretical framework of Semioticsbased Manufacturing Systems Integration [1] and [2] and presents its practical implementations, validation and implications in industrial environments.

The main research thesis is that the assessment processes (within the CE readiness assessment) are interpretation dependent and, therefore, the application of traditional prescriptive methodologies may lead to failure or serious challenge of the projects. Further, as a second part of the thesis, that the application of a pragmatics-based approach might significantly improve potential for successful implementation of $\mathrm{CE}$ is validated.

As an approach to a CE implementation strategy, the methodology based on the so-called simultaneity matrices (also called concurrency matrices) is used, for which two different interpretations are compared. The proposed methodology is validated in a reallife environment, i.e. in two SME manufacturing companies, which have planned to apply CE. The results confirm the expectations that different interpretations may imply different management decisions and, therefore, corrupt the best possible decision. Consequently, in order to assure the best decisions for the case under consideration, an improved methodology for $\mathrm{CE}$ implementation strategy (including the CE Readiness Assessment (CERA)), should include multiple interpretations, i.e. should apply the pragmatics-based approach.

The relevance of the research is multifold:

i) Although the $\mathrm{CE}$ concept has existed for over two decades, companies still struggle to implement it to its full capacity. In addition, despite CE developments towards collaborative engineering, no alternative approach that paradigmatically negates or eliminates the $\mathrm{CE}$ as obsolete has surfaced yet. In other words, the CE implementation projects have been reaffirmed as currently being valid;

ii) In the present market, characterized by high levels of uncertainty, companies are in search of low costs and short implementation times, and trusted technologies. In fact, up to $70 \%$ of all new projects fail or are somehow challenged (The percentages are different by different sectors) [3]. Therefore, it is not surprising that companies are reluctant to implement new organizational projects. This implies the need for reliable CE implementation methodologies; 
iii) While it is evident that use of advanced computer technologies contributes to a reduction of the throughput time of $\mathrm{CE}$ implementation processes, providing more efficiency and speed in the processes, the role of technology-oriented approaches to reduce the $\mathrm{CE}$ implementation projects failure rate is less obvious, if not detrimental. In reality, the top five factors of project success are not technological [3]. In other words, "Tools by themselves do not promote success; the proper use of the tools does." [3]. Accordingly, we promote non-technological approaches, such as a pragmatics-(i.e. semiotics)based approach to CE implementation strategy;

iv) This paper provides validation of the pragmaticsbased approach to $\mathrm{CE}$ implementation methodology, with respect to simultaneity of processes.

Therefore, the primary objective of the paper is to investigate the influence of a pragmaticsbased approach on CE implementation projects and particularly evaluation of process simultaneity, as one of the main features of a CE implementation strategy and a $\mathrm{CE}$ readiness assessment. In order to facilitate the application of $\mathrm{CE}$ in a wider range of companies, the secondary objective of the paper is to contribute to the development and improved methodology of pragmatics-based $\mathrm{CE}$ implementation methodology.

This paper is organized in nine sections. After the introduction, Section 2 briefly presents pragmatics as the underlying meta-theoretical approach, in the context of the above-mentioned relevance factors. Section 3 summarizes basic requirements for and principles of CE. Section 4 presents an overview of the CERA methodology and the (CE) process simultaneity assessment methodologies (as an integral part of the CE implementation strategy). Therefore, the state-of-the-art is presented throughout the third and fourth section. The new methodology is outlined in Section 5. Section 6 presents two case studies. This section represents a validation of the thesis on the influence of pragmatics-based approaches on the CE implementation project, and specifically of the evaluation of the simultaneity of processes, as well as on the identification of intervention areas for $\mathrm{CE}$ implementation. A mold-making company was chosen for the first case study and a manufacturer of energy engineering products and systems for the second. Both companies are SMEs, and have well-developed designs and production. Secondary data, already reported in [4], were used for the first case study. For the second case study, the primary data were used. Section 6 presents research results analysis and
Section 7 provides conclusions and recommendations for future research. Finally, Section 8 presents the references.

\section{PRAGMATICS}

In addition to syntax and semantics, pragmatics is field of semiotics, which is the science of signs. Probably the most used definition of the syntax, semantics and pragmatics is by Morris [5]:

" $[P]$ ragmatics is that portion of semiotics which deals with the origin, uses and effects of signs within the behavior in which they occur; semantics deals with the signification of signs in all modes of signifying; syntax deals with combination of signs without regard for their specific significations or their relation to the behavior in which they occur."

While the other two fields of semiotics, syntax and semantics, are already well known and widely used in manufacturing, or production systems, pragmatics is a new approach that deals with interpretations and their effects on the analysis and construction (i.e. project, or design) studies.

As a means of, among other benefits, overcoming the problems of failing project rates, the assumption is that pragmatics could be used as a perspective for analyzing and constructing manufacturing systems [1] and [2], and consequently also applied to CE issues. Pragmatics/semiotics address non-technological aspects of organization.

In the research presented in this paper, pragmatics is used as a perspective for analyzing and constructing manufacturing systems: CE implementation projects, specifically. In particular, as a part of the processes simultaneity and CE readiness, the assessment, modeling and effects of different interpretations, as pragmatic aspects, are studied.

\section{CE CHARACTERIZATION}

$\mathrm{CE}$ is characterized, by three basic global characteristics:

1) Simultaneity of processes. Fig. 1a presents the signature structure of the Time-to-Market (TTM), denoted $\mathrm{T}$, in sequentially performed operations, denoted $\mathrm{OP}_{i}$, where $T$ is equal to the sum of time duration $t_{i}$ of each operation $\mathrm{OP}_{\mathrm{i}}$, i.e. $T=\sum_{i=1}^{n} t_{i}$. In the case of the maximum simultaneity of operations, the Time-to-Market (TTM), denoted $T$, is equal to the time duration of the operation with maximum time duration, i.e. $T=\max \left(t_{i}\right) \mid i$ $=1, \ldots, n$. Fig. $1 \mathrm{~b}$ presents the signature structure for $T$ for the operations performed with certain 
degree of simultaneity, which is a realistic case, i.e. $T$ value is between the $T$ for sequentially performed operations and $T$ for four operations performed simultaneously (Figs. 1a and b) $\left(\max \left(t_{1}, t_{2}, t_{3}, t_{4}\right)<T<\left(t_{1}+t_{2}+t_{3}+t_{4}\right)\right)$. In effect, for the operations performed simultaneously, or with a degree of simultaneity, there is a compression of TTM;

2) Concurrency, through multifunctional teams (teamwork) that concurrently and interactively make decisions on new product development (NPD). Simultaneity of operations (processes) does not assure concurrency per se. In the case of simple simultaneity, there is no interactive communication. The communication is reduced to the communication of the conditions for starting another operation that may be performed simultaneously (in parallel) and at its completion. The true concurrent performance of the two operations implies an interactivity between the two operations in order to make the best decision, i.e. the two operations 'concur' simultaneously for the best decision through dynamic interactions (communication), or solutions. This is illustrated in Fig. 2b;

3) The effort of 2) and 3) from or in the early stage of the NPD process, i.e. in the phase of design (Fig. 3).

These three basic/primary/global features, called the main $\mathrm{CE}$ parameters/characteristics, are used as the basic criteria for evaluation of the level of $\mathrm{CE}$ readiness and consequent applicability in a company.

Probably the most cited definition of $\mathrm{CE}$ is by Winner [6]:

" $\mathrm{CE}$ is a systematic approach to the integrated, concurrent design of products and their related processes, including manufacture and support. This approach is intended to cause the developers, from the outset, to consider all elements of the product life cycle from conception through disposal, including quality, cost, schedule, and user requirements."

and

"CE is a system for the achievement of (or, at least, the engineering approximation of) the best possible combination of these objectives."

Although considered synonyms, Simultaneous Engineering (SE) and $\mathrm{CE}$ are qualitatively different (similar situation occurs with collaborative engineering). Both concepts imply simultaneity of the processes, but $\mathrm{CE}$ also implies mutual communication among workers from different functional areas. This difference is graphically presented in Fig. 2. An example of SE, i.e. Simultaneous Product
Development, which implements many of the elements from $\mathrm{CE}$, is given in [7].

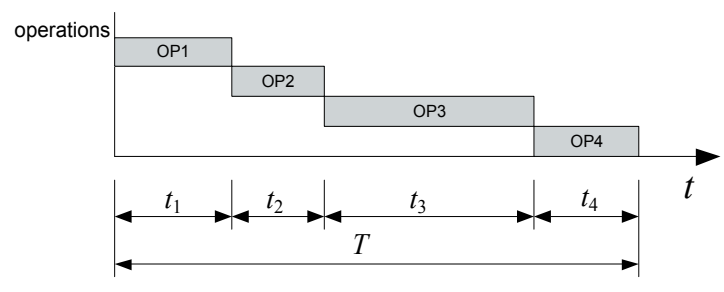

a) $T=t_{1}+t_{2}+t_{3}+t_{4}$

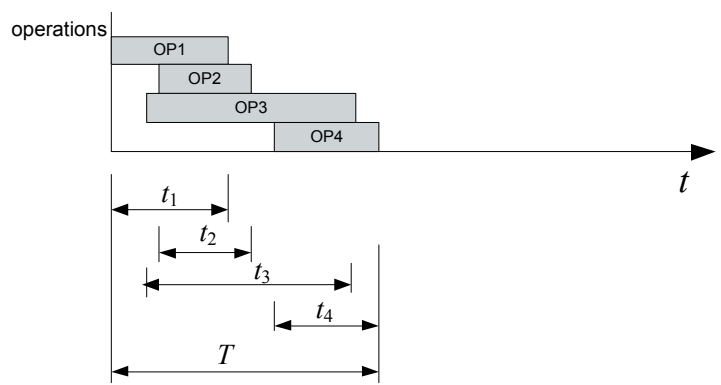

b) $\max \left(t_{1}, t_{2}, t_{3}, t_{4}\right)<T<\left(t_{1}+t_{2}+t_{3}+t_{4}\right)$

Fig. 1. a) Time-To-Market (TTM or T) of sequentially performed processes, and b) realistic TTM (T) compression by achievable degree of processes simultaneity
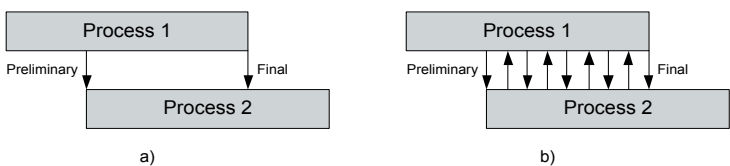

Fig. 2. a) Simultaneous (overlapped) execution of processes; $b$ ) Concurrent execution of processes (adapted from [8])

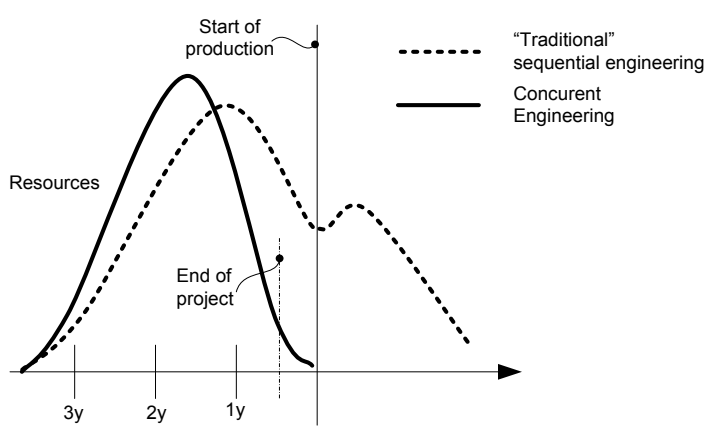

Fig. 3. Resources function pattern shapes for traditional sequential, or functional, engineering and CE (adapted from [9])

\section{CE READINESS AND PROCESS SIMULTANEITY ASSESSMENT}

\subsection{CE Readiness Assessment}

Readiness assessment, as a part of a global CE implementation framework, is one of the first phases 
in the $\mathrm{CE}$ implementation process. Its significance is in determining the concrete mechanisms and degree of details necessary to deploy it. The CE implementation model, presented in Fig. 4 is adopted as the reference model.

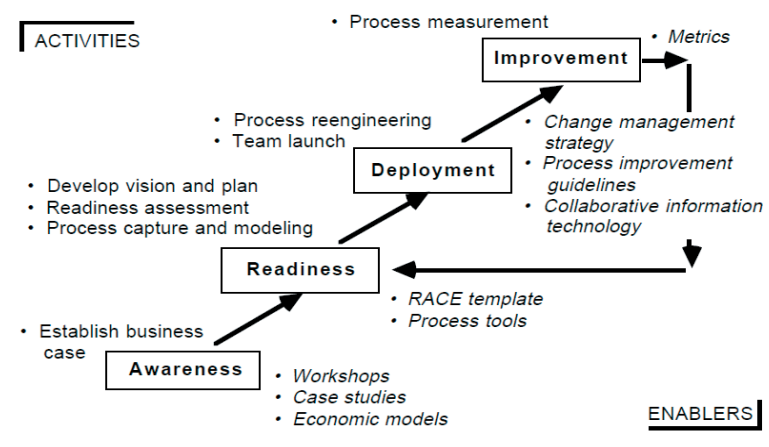

THE CE TRANSFORMATION PROCESS

Fig. 4. CE implementation strategy [10]

RACE (Readiness Assessment for Concurrent Engineering) model, which is almost certainly the most used methodology for this purpose, has been developed within this framework. It consists of assessment in two key areas: firstly, a product development process and practices; secondly, a technology, and corresponding nine and five subareas respectively:

"The process component encompasses nine major elements and follows a readiness scale adapted from SEI's CMM [3]. These elements are customer focus, process focus, strategies for team formation and development, accommodation of teams within the organization, management systems, mechanisms for rapid product assurance, agility, senior leadership commitment, and discipline. The technology component covers five areas, namely, application tools, communication, coordination, information sharing services, and integration" [10].

For each sub-area, the critical elements and the key criteria are defined. A questionnaire (manual or computer-based) is used for data gathering.

This method has been used as a source for a number of other methods that adapted or modified the original RACE method. In [11] a good overview is presented, including an analysis of their characteristics, of these methods as well as of some others. [11] cites PMO (The Process Model of Organization), PMO-RACE (A Combination of PMO \& RACE), PRODEVO (A Swedish Model Based on RACE), CMM (Capability Maturity Model), SPICE (Standardized Process Improvement for Construction
Enterprises), Project Management Process Maturity (PM), CERAMConstruct model.

The difference between CERA (Concurrent Engineering Readiness Assessment) and RACE (Readiness Assessment for Concurrent Engineering) is that CERA is a generic name of the methodology while the RACE is the name of the methodology formulated by the Concurrent Engineering Research Center (CERC) at West Virginia University. Therefore, RACE functions as a product name. Both CERA and RACE refer to the same problem. A number of similar methodologies are derived from RACE.

In addition to the previous overview see also [12] and [13].

\subsection{Process Simultaneity (Parallelism) Assessment}

Process simultaneity, or process parallelism, is one of the hallmarks of CE. However, apparently little attention has been paid to measuring it. Usually, measures of the process simultaneity/parallelism are adopted from the network theories, i.e. from the activity network analysis applied to project management models. A study presented in [14], which is virtually the only source that explicitly analyzes process simultaneity/parallelism in the context of CE, also provides a good overview of several relevant methods. The study concludes that the measures (which are analyzed in the study, and which are the methods defined primarily for the analysis of activity networks) are not sufficient and the authors proposed a new measure, named $W$, and its relative measure $w$ (See Eqs. (1) and (2)), which by the examples analyzed in [14] show much better performance. The results indicate that $W$ is an excellent measure of parallelism, particularly for application in concurrent engineering. [14].

Another measure, based on the so-called Simultaneity (Concurrency) Matrix (SCM), was presented in [15]. This measure is used to evaluate degree of simultaneity through the 3-value function $d_{C E}$ of the degree of the particular unit's participation in the particular product development phase [15] and [4]. Concerning the proposed pragmatics-based approach to simultaneity assessment, the SCM is probably the most appropriate and easier to use, giving three-value graded evaluations, and providing an easier basis for evaluation of interpretations. Therefore, in this paper, the methodology based on SCM is applied. It is worth noting that the use of the simultaneity/concurrency matrix does not prevent use of other measures of the processes simultaneity. 


\subsubsection{Process Simultaneity Assessment}

The $W$ measure and its relative measure $w$ of the process simultaneity/parallelism (in the context of $\mathrm{CE})$, were defined in [14] as:

$$
\begin{gathered}
W=(N-L), \\
w=W / N=(N-L) / N,
\end{gathered}
$$

where $N$ is the number of activities in the network; $L$ is the length of the activity network, i.e. maximum number of activities in series, and $w$ is the fraction of the activities that are in parallel.

\subsubsection{Process Simultaneity Assessment: SCM and $D_{C E}$}

The methodology primarily evaluates the simultaneity of processes, i.e. the above-listed first $\mathrm{CE}$ characteristic, and could be also used to evaluate global distribution of the effort, i.e. the third CE characteristic. The analysis is presented through the matrices organizational units $\times$ phases (used as a short name for product development phases). They indicate the main functions in the functional organization (the company's organizational units that participate in the product development phases) and the main phases of the product development life cycle. The matrix cell represents the function of the particular unit's participation in the particular product development phase or process.

For the particular product development phase, the cells are filled by the three-value function $d_{C E}=f$ (org_unit, process) where $d_{C E} \in\{0,0.5,1\}$. The values mean: ' 1 ' full and active participation; ' 0.5 ' partial participation; and ' 0 ' no participation of the particular unit in the particular product development phase. When two or more particular units participate in a particular product development phase, it means that these activities are performed in parallel, i.e. simultaneously.

The total degree of simultaneity/ concurrency, $D_{C E}$, for a company (for all the company's units that participate in the new product development) is calculated as the sum of all $d_{C E}$ in all columns divided by the number of matrix cells:

$$
D_{C E}=\frac{\sum_{i=1}^{n} \sum_{j=1}^{m} d_{C E i, j}}{m \cdot n} \cdot 100[\%],
$$

where $m$ is number of organizational units and $n$ number of "new product development" phases.
A relative measure is not necessary to define as the measure $D_{C E}$ is expressed in percentage. An example of the three-value SCM is given in Fig. 5.

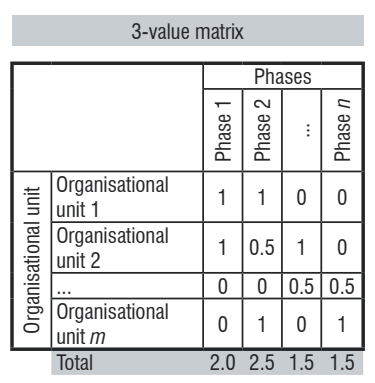

Fig. 5. An example of the $4 \times 4$ three-value SCM, with the total degree of simultaneity / concurrency for a company of $47 \%$.

\section{PRAGMATICS-BASED METHODOLOGY FOR CE IMPLEMENTATION AND INTERPRETED SCM}

\subsection{Interpreted SCM}

Pragmatics-based methodology focuses on interpretations and not on the originally declared values by the examinees. It means that once responses from the examinees are gathered in some form, for example in the form of the SCM (or e.g. in the form of activity network graphs), different possible interpretations of the responses are examined and analyzed. Here, we examine interpretations of the original identifications of the processes simultaneity in the form of SCM.

With different interpretations of the original 3 -value matrix, new matrices are produced, each one corresponding to one interpretation, with differently defined simultaneity degrees, $d_{C E}$.

In consideration of which scores of the matrix's cells to interpret and how, the most relevant are those with the scores of $d_{C E}$ equal to 0.5 . Scores of 1 , and especially 0 , due to their nature, describe real life processes with much more certainty, while 0.5 scores involve certain level of uncertainty about quality and quantity, in terms of regularity, frequency, content, extension, volume, etc. Therefore, it is more appropriate to interpret 0.5 scores as having different values in reality.

In fact, the real values, or more precisely, the values perceived as real, depend of individual and collective interpretations. In other words, the values perceived as real are the results of interpretations processes and negotiations of interpretations among stakeholders, which is the issue belonging to the field of pragmatics. Therefore, for the purpose of 
our research, we would suggest two interpretations (probably the most appropriate ones):

$$
I_{1}: \quad 0.5 \rightarrow 0 \quad \text { and } I_{2}: \quad 0.5 \rightarrow 1 .
$$

The first interpretation, $I_{1}$, a conservative interpretation, because it considers only regular interactions, and neglects the irregular, sporadic, minor and incomplete processes, which is more rigorous interpretation of the processes.

The second interpretation, $I_{2}$, an inclusive interpretation, because it considers (or includes) all interactions as valuable, whether regular or irregular, which is a looser, i.e. a more inclusive interpretation of the processes.

Applying interpretations $I_{1}$ and $I_{2}$, the original 3 -value matrix yields two new matrices, whose cells are filled by the 2-value function: $d_{C E}=f$ (org_unit, process) where $d_{C E} \hat{\mathrm{I}}\{0,1\}$.

The new matrix created by the conservative interpretation $I_{1}$ is called the conservative matrix and the new matrix created by the inclusive interpretation $I_{2}$ is called the inclusive matrix. To distinguish 2-value (conservative and inclusive) matrices from the 3-value matrices (called SCM), they are called interpreted SCM.

Fig. 6 schematically presents an interpretation of the initial 3-value matrix and its transformation in two 2-value interpreted (Conservative and Inclusive) matrices, where scores 0.5 , associated with irregular participation, are interpreted.

\subsection{Procedure Outline for Application of the Pragmatics- Based Approach}

Application of Pragmatics-Based Approach will be demonstrated through creation of 'Interpreted SCM', for process simultaneity assessment, in three phases of the Concurrent Engineering implementation methodology. These phases are:

1) identification of the current "As-Is" situation,

2) identification of the company's goals, i.e. To-Be scenario, regarding the desired future level of the CE application, and

3) identification of the domain where the main actions of further development and application of CE should take place, as the difference between the To-Be and As-Is scenarios.

The application procedure can be outlined through the following steps: Procedure outline

1. Identification of the current As-Is situation: creation of 3-value As-Is SCM

$\rightarrow$ creation of 3-value As-Is.

2. Identification of the company's goals, i.e. ToBe scenario, regarding the desired future level of the CE application: creation of 3-value To-Be SCM

$\rightarrow$ creation of 3-value $\mathbf{T o}-\boldsymbol{B} \boldsymbol{e} \mathrm{SCM}$.

3. Identification of the domain where the main actions of further development and application of $\mathrm{CE}$ should take place, i.e. identification of intervention areas for $\mathrm{CE}$ implementation, as the difference between the matrices To-Be and As - Is $\rightarrow$ creation of 3-value "Difference" "SCM".

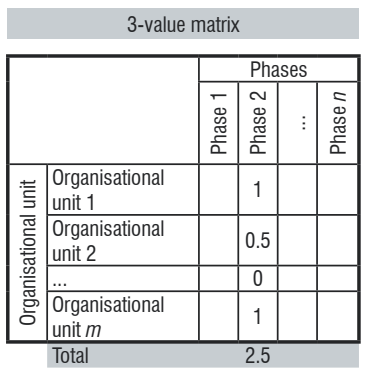

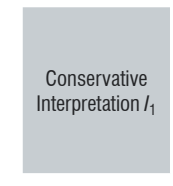
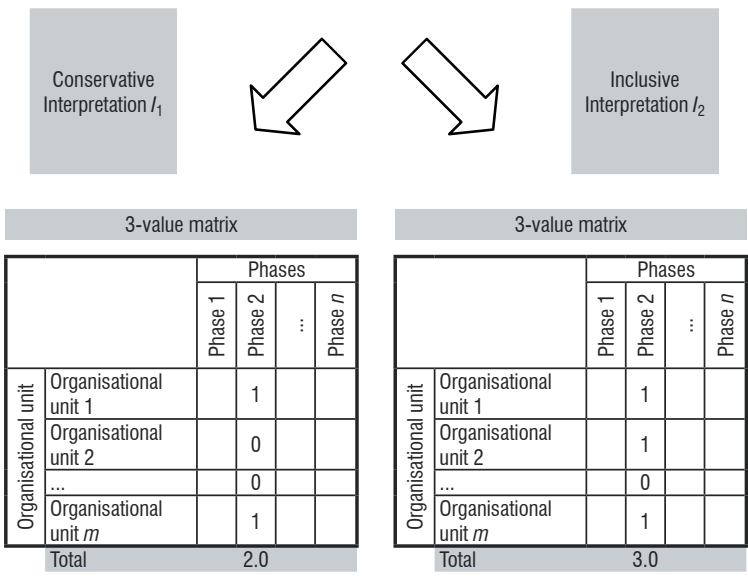

Fig. 6. Interpretation of the 3-value matrix and its transformation in two 2-value interpreted (conservative and inclusive) matrices

4 Interpretations $I_{1}$ and $I_{2}$ of the current "As-Is" situation:

4.1 Interpretation $I_{1}$ of the current " $A s-I_{s}$ " situation

$\rightarrow$ creation of 2-value "As-Is" conservative interpreted SCM.

4.2 Interpretation $I_{2}$ of the current "As-Is" situation

$\rightarrow$ creation of 2-value "As-Is" inclusive interpreted SCM.

5. Interpretations $I_{1}$ and $I_{2}$ of the company's goals, i.e. "To-Be" scenario: 
5.1 Interpretation $I_{1}$ of the company's goals, i.e. "To-Be" scenario, regarding future level of the CE application,

$\rightarrow$ creation of 2-value "To-Be" conservative interpreted $\mathrm{SCM}$.

5.2 Interpretation $I_{2}$ of the company's goals, i.e. "To-Be" scenario, regarding future level of the CE application,

$\rightarrow$ creation of 2-value " $\boldsymbol{T o}$ - $\boldsymbol{B} \boldsymbol{e}$ " inclusive interpreted $\mathrm{SCM}$.

6. Identification of the domain where the main actions of further development and application of $\mathrm{CE}$ should take place, i.e. identification of intervention areas for $\mathrm{CE}$ implementation based on Interpretations $I_{1}$ and $I_{2}$ :

6.1 Identification of the domain where the main actions of further development and application of CE should take place, as the difference between the interpreted matrices "To-Be" and "As-Is" based on Interpretation $I_{1}$

$\rightarrow$ creation of 2-value "Difference" SCM conservative interpreted.

6.2 Identification of the domain where the main actions of further development and application of CE should take place, as the difference between the interpreted matrices "To-Be" and "As-Is" based on Interpretation $I_{2}$

$\rightarrow$ creation of 2-value "Difference" SCM inclusive interpreted.

7. Analysis and negotiation of the values to adopt for consideration in the next phases of the CE implementation.

Phase 3 could be circumvented as it is not relevant for the pragmatics-based approach, because it is created over non-interpreted SMC and, therefore, generates incorrect results; the relevant results are only the differences of the interpreted matrices. The analysis implies calculation of the simultaneity degrees of each of the scenarios in order to provide the base for the "negotiation" of the values to be adopted.

In order to compare the results, two measures of the processes simultaneity evaluation will be applied: 1) $D_{C E}$, measure, and 2) Omega measures $W$ and $w$.

\section{CASE STUDIES}

\subsection{Companies Presentation and Business Requirements}

Two case studies were conducted in two companies. Company A, in Case Study 1, is an SME mold producer, located in Portugal. Company B, in Case Study 2, located in a transition country, is an energy equipment manufacturer SME. Both companies integrate typical functions and new product development phases inherent to the $\mathrm{CE}$ domain definition, i.e. from marketing through design and production to shipping. For both companies, the question under consideration is what the engineering I manufacturing strategy that would improve the company's performance be, and how to identify the company's internal functional domains and organizational units as domains for implementation of that strategy?

The engineering/manufacturing strategy, or concept, needed to adopt and implement, should be capable of achieving the following outcomes:

Qualitative:

1) providing maximal customer satisfaction and the maximum quality of products in accordance with the customer's specifications / requirements; 2) enhancing the company's competitiveness on the market;

Quantitative:

3a) reducing the product time to market (for Company A);

$3 \mathrm{~b})$ reducing the percentage of redesign and customer complaints for $40 \%$ in the following 3 years (for Company B).

From among different strategies considered, CE has been selected as the candidate strategy. All three requirements suggest the use of $\mathrm{CE}$.

\subsection{Organization of the assessment process}

Questionnaires were used for data collection in both cases. The questionnaire's content was the empty table of Simultaneity (Concurrency) Matrix (SCM). The respondents had to fill in the organizational units (the "Functions" column) and the new product development phases (the "Phase" row) in their company, as well as to attribute values for $d_{C E} \in\{0$, $0.5,1\}$ for each matrix cell. As the two companies have slightly different organization as well as new product development phases, the tables from the two companies slightly differ. The respondents were representatives from all the organizational units that participate in the product development process chain. They have responded to two questionnaires, one of which collected data for the As-Is situation and the second for the To-Be scenario. The second questionnaire was designed to capture information about desired degrees of simultaneity and collaboration along the product development life-cycle, in accordance with the principle of multifunctional $\mathrm{CE}$ approach to the product development and multifunctional $\mathrm{CE}$ teams. 
Table 1. As-ls and To-Be (in ( )) - 2 values matrices by conservative interpretation $I_{1}$

\begin{tabular}{|c|c|c|c|c|c|c|}
\hline Function & $\begin{array}{l}\text { 흘 } \\
\text { 퓽 } \\
\text { 응 }\end{array}$ & 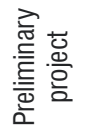 & 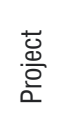 & 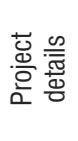 & 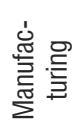 & 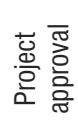 \\
\hline Client & $1(1)$ & $1(1)$ & $1(1)$ & $0(1)$ & $0(0)$ & $1(1)$ \\
\hline Techn.-Commerc. & $1(1)$ & $1(1)$ & $1(1)$ & $0(1)$ & $0(0)$ & 1(1) \\
\hline Design-CAD & $1(1)$ & $1(1)$ & $1(1)$ & $1(1)$ & $0(0)$ & $0(0)$ \\
\hline Planning & $0(0)$ & $0(1)$ & $1(1)$ & $0(1)$ & $1(1)$ & $0(0)$ \\
\hline Purchase & $0(0)$ & $1(1)$ & $0(1)$ & $1(1)$ & $1(1)$ & $0(0)$ \\
\hline Suppliers & $0(0)$ & $0(1)$ & $1(1)$ & $1(1)$ & $0(0)$ & $0(0)$ \\
\hline Programming - CAM & $0(0)$ & $0(1)$ & $0(1)$ & $0(1)$ & $1(1)$ & $0(0)$ \\
\hline Production & $0(0)$ & $0(1)$ & $0(1)$ & $0(1)$ & $1(1)$ & $0(0)$ \\
\hline Finishing-Assembly & $0(0)$ & $0(1)$ & $0(1)$ & $0(1)$ & $1(1)$ & $1(1)$ \\
\hline Try outs & $0(0)$ & $0(1)$ & $1(1)$ & $0(1)$ & $1(1)$ & 1(1) \\
\hline Quality Control & $0(0)$ & $0(1)$ & $1(1)$ & $0(1)$ & $1(1)$ & $1(1)$ \\
\hline
\end{tabular}

Table 2. As-ls and To-Be (in ( )) - 2 values matrices by inclusive interpretation $\mathrm{I}_{2}$

\begin{tabular}{|c|c|c|c|c|c|c|}
\hline Function & $\begin{array}{l}\text { 을 } \\
\text { 竞 } \\
\text { 。 }\end{array}$ & 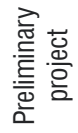 & $\begin{array}{l}\text { 멈 } \\
\frac{.0}{0} \\
\frac{0}{2}\end{array}$ & 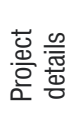 & 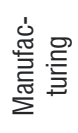 & 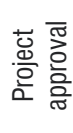 \\
\hline Client & $1(1)$ & $1(1)$ & $1(1)$ & $0(1)$ & $0(0)$ & $1(1)$ \\
\hline Techn.-Commerc. & $1(1)$ & $1(1)$ & $1(1)$ & $0(1)$ & $1(1)$ & $1(1)$ \\
\hline Design-CAD & $1(1)$ & $1(1)$ & $1(1)$ & $1(1)$ & $0(0)$ & $0(0)$ \\
\hline Planning & $1(1)$ & $1(1)$ & $1(1)$ & $1(1)$ & $1(1)$ & $0(0)$ \\
\hline Purchase & $1(1)$ & $1(1)$ & $1(1)$ & $1(1)$ & $1(1)$ & $0(0)$ \\
\hline Suppliers & $1(1)$ & $1(1)$ & $1(1)$ & $1(1)$ & $0(0)$ & $0(0)$ \\
\hline Programming - CAM & $0(0)$ & $0(1)$ & $1(1)$ & $1(1)$ & $1(1)$ & $0(0)$ \\
\hline Production & 1(1) & 1(1) & $1(1)$ & $1(1)$ & 1(1) & $0(0)$ \\
\hline Finishing-Assembly & $0(0)$ & $0(1)$ & $0(1)$ & $1(1)$ & $1(1)$ & 1(1) \\
\hline Try outs & $0(0)$ & $0(1)$ & $1(1)$ & $0(1)$ & $1(1)$ & $1(1)$ \\
\hline Quality Control & $0(0)$ & $0(1)$ & $1(1)$ & $1(1)$ & 1(1) & $1(1)$ \\
\hline
\end{tabular}

Table 3. Difference 2 values matrices between To-Be and As-IS matrices (conservative interpretation and inclusive interpretation)

\begin{tabular}{|c|c|c|c|c|c|c|}
\hline Function & $\begin{array}{l}\text { 음 } \\
\text { 売 } \\
\text { 응 }\end{array}$ & 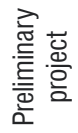 & 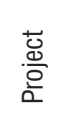 & 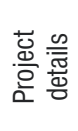 & 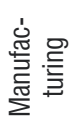 & 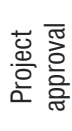 \\
\hline Client & $0(0)$ & $0(0)$ & $0(0)$ & $1(1)$ & $0(0)$ & $0(0)$ \\
\hline Techn.-Commerc. & $0(0)$ & $0(0)$ & $0(0)$ & $1(1)$ & $0(0)$ & $0(0)$ \\
\hline Design-CAD & $0(0)$ & $0(0)$ & $0(0)$ & $0(0)$ & $0(0)$ & $0(0)$ \\
\hline Planning & $0(0)$ & $1(0)$ & $0(0)$ & $1(0)$ & $0(0)$ & $0(0)$ \\
\hline Purchase & $0(0)$ & $0(0)$ & $1(0)$ & $0(0)$ & $0(0)$ & $0(0)$ \\
\hline Suppliers & $0(0)$ & $1(0)$ & $0(0)$ & $0(0)$ & $0(0)$ & $0(0)$ \\
\hline Programming - CAM & $0(0)$ & $1(1)$ & $1(0)$ & $1(0)$ & $0(0)$ & $0(0)$ \\
\hline Production & $0(0)$ & $1(0)$ & $1(0)$ & $1(0)$ & $0(0)$ & $0(0)$ \\
\hline Finishing-Assembly & $0(0)$ & $1(1)$ & $1(1)$ & $1(0)$ & $0(0)$ & $0(0)$ \\
\hline Try outs & $0(0)$ & $1(1)$ & $0(0)$ & $1(1)$ & $0(0)$ & $0(0)$ \\
\hline Quality Control & $0(0)$ & $1(1)$ & $0(0)$ & $1(0)$ & $0(0)$ & $0(0)$ \\
\hline
\end{tabular}

These data pertain to the simultaneity of the processes among the organizational units along the product development line.

\subsection{Case Study 1 - Company A Data for Process Simultaneity Assessment: SCMs for the Company A}

The assessment results for Company A are summarized in Tables 1 and 2, which are of the organizational units $\times$ phases matrix type. They are created in the $4^{\text {th }}$ and $5^{\text {th }}$ steps of the procedure outlined in Section 5.2, and present the interpreted matrices for conservative and inclusive interpretations of the As-Is situation and ToBe scenario, respectively. Table 3 , created in the $6^{\text {th }}$ step, presents the Difference matrix, i.e. presents the differences between the To-Be and As-Is matrices by conservative and inclusive interpretations.

\subsection{Case Study 2 - Company B Data for Process Simultaneity Assessment: SCMs for the Company B}

The assessment results for Company B are summarized in Tables 4 and 5, which are of the organizational units $\times$ phases matrix type. They are conservative and inclusive interpretations of the As-Is situation and To-Be scenario, respectively.

Table 6 presents the differences between these matrices. The same procedure is used as in Case Study 1 (Section 6.2).

\section{RESULTS ANALYSIS}

Through the analysis of the interpreted data we can make the assessment of:

1) Simultaneity of the processes - CE parameter 1 (Section 2) and

2) Differences in simultaneity assessment between two interpretations (the primary research thesis).

The influence of interpretations, as the intrinsic feature of the pragmatics-based assessment of the simultaneity of processes, is highly significant. The results of quantitative evaluation are presented in Table 7. The influence evaluation/quantification process proceeded in the following way:

The simultaneity of the processes was assessed for both case studies and two interpretations $I_{1}$ and $I_{2}$, (conservative and inclusive), by calculating simultaneity measures $D_{C E}, W$, and $w$. The results for the As-Is situation and To-Be scenario and their difference are summarized in columns 3 and 4 of Table 7. Subsequently, differences in simultaneity assessment between two interpretations, for each 
Table 4. As-Is and To-Be (in ( )) - 2 values matrices by conservative interpretation $I_{1}$

\begin{tabular}{lccccccccc}
\hline Org. Unit & Phase & $\begin{array}{c}\text { Preliminary } \\
\text { project }\end{array}$ & Quotation & Contracting & Project & $\begin{array}{c}\text { Product } \\
\text { plann }\end{array}$ & $\begin{array}{c}\text { Product } \\
\text { launch }\end{array}$ & Production & Testing \\
\hline Marketing \& selling & $1(1)$ & $1(1)$ & $1(1)$ & $0(1)$ & $0(1)$ & $0(1)$ & $0(1)$ & $0(1)$ & $1(1)$ \\
\hline Design commercial & $1(1)$ & $0(1)$ & $0(1)$ & $1(1)$ & $0(1)$ & $0(1)$ & $0(1)$ & $0(1)$ & $0(0)$ \\
\hline Process planning & $0(1)$ & $0(1)$ & $0(0)$ & $0(1)$ & $0(1)$ & $0(1)$ & $0(1)$ & $0(1)$ & $0(0)$ \\
\hline Product planning & $0(1)$ & $0(0)$ & $0(0)$ & $0(1)$ & $1(1)$ & $1(1)$ & $1(1)$ & $0(0)$ & $0(1)$ \\
\hline Purchasing & $0(1)$ & $0(1)$ & $0(1)$ & $0(1)$ & $1(1)$ & $0(1)$ & $1(1)$ & $0(0)$ & $0(0)$ \\
\hline Finance & $0(1)$ & $0(1)$ & $0(1)$ & $0(1)$ & $1(1)$ & $0(1)$ & $0(1)$ & $0(1)$ & $0(1)$ \\
\hline Human resources & $1(1)$ & $1(1)$ & $1(1)$ & $1(1)$ & $0(1)$ & $0(1)$ & $1(1)$ & $0(1)$ & $0(1)$ \\
\hline Logistics & $0(0)$ & $0(1)$ & $0(1)$ & $0(0)$ & $1(1)$ & $1(1)$ & $0(1)$ & $0(1)$ & $1(1)$ \\
\hline Production & $0(0)$ & $0(0)$ & $0(0)$ & $0(1)$ & $0(1)$ & $0(1)$ & $1(1)$ & $0(1)$ & $0(1)$ \\
\hline Maintenance & $0(0)$ & $0(0)$ & $0(0)$ & $0(0)$ & $0(1)$ & $0(1)$ & $1(1)$ & $0(1)$ & $0(1)$ \\
\hline Quality control (Inspection) & $0(0)$ & $0(0)$ & $0(0)$ & $0(1)$ & $0(1)$ & $0(1)$ & $1(1)$ & $0(1)$ & $0(1)$ \\
\hline Laboratory testing & $0(1)$ & $0(1)$ & $0(1)$ & $0(1)$ & $0(1)$ & $0(1)$ & $0(1)$ & $1(1)$ & $0(1)$ \\
\hline Transport & $0(0)$ & $0(0)$ & $0(0)$ & $0(1)$ & $0(1)$ & $0(1)$ & $1(1)$ & $1(1)$ & $1(1)$ \\
\hline Total & $3(8)$ & $2(8)$ & $2(7)$ & $2(12)$ & $4(13)$ & $2(13)$ & $7(13)$ & $2(11)$ & $3(10)$ \\
\hline
\end{tabular}

Table 5. As-ls and To-Be (in ( )) - 2 values matrices by inclusive interpretation $I_{2}$

\begin{tabular}{lccccccccc}
\hline Org. Unit & Phase & $\begin{array}{c}\text { Preliminary } \\
\text { project }\end{array}$ & Quotation & Contracting & Project & $\begin{array}{c}\text { Product } \\
\text { plann }\end{array}$ & $\begin{array}{c}\text { Product } \\
\text { launch }\end{array}$ & Production & Testing \\
\hline Marketing \& selling & $1(1)$ & $1(1)$ & $1(1)$ & $1(1)$ & $1(1)$ & $1(1)$ & $1(1)$ & $0(1)$ & $1(1)$ \\
\hline Design commercial & $1(1)$ & $1(1)$ & $1(1)$ & $1(1)$ & $1(1)$ & $0(1)$ & $1(1)$ & $1(1)$ & $0(1)$ \\
\hline Process planning & $1(1)$ & $1(1)$ & $0(1)$ & $1(1)$ & $1(1)$ & $0(1)$ & $1(1)$ & $0(1)$ & $0(1)$ \\
\hline Product planning & $0(1)$ & $0(1)$ & $0(1)$ & $0(1)$ & $1(1)$ & $1(1)$ & $1(1)$ & $0(1)$ & $0(1)$ \\
\hline Purchasing & $1(1)$ & $1(1)$ & $0(1)$ & $1(1)$ & $1(1)$ & $0(1)$ & $1(1)$ & $0(1)$ & $0(1)$ \\
\hline Finance & $1(1)$ & $1(1)$ & $1(1)$ & $1(1)$ & $1(1)$ & $1(1)$ & $1(1)$ & $0(1)$ & $0(1)$ \\
\hline Human resources & $1(1)$ & $1(1)$ & $1(1)$ & $1(1)$ & $1(1)$ & $1(1)$ & $1(1)$ & $1(1)$ & $1(1)$ \\
\hline Logistics & $0(1)$ & $0(1)$ & $0(1)$ & $0(1)$ & $1(1)$ & $1(1)$ & $1(1)$ & $0(1)$ & $1(1)$ \\
\hline Production & $0(1)$ & $0(1)$ & $0(1)$ & $0(1)$ & $1(1)$ & $1(1)$ & $1(1)$ & $1(1)$ & $1(1)$ \\
\hline Maintenance & $0(1)$ & $0(1)$ & $0(1)$ & $0(0)$ & $0(1)$ & $0(1)$ & $1(1)$ & $1(1)$ & $1(1)$ \\
\hline Quality control (Inspection) & $0(1)$ & $0(1)$ & $0(1)$ & $0(1)$ & $1(1)$ & $1(1)$ & $1(1)$ & $1(1)$ & $1(1)$ \\
\hline Laboratory testing & $0(1)$ & $0(1)$ & $0(1)$ & $0(1)$ & $0(1)$ & $0(1)$ & $0(1)$ & $1(1)$ & $1(1)$ \\
\hline Transport & $0(0)$ & $0(1)$ & $0(1)$ & $0(1)$ & $0(1)$ & $0(1)$ & $1(1)$ & $1(1)$ & $1(1)$ \\
\hline Total & $6(12)$ & $6(13)$ & $4(13)$ & $6(13)$ & $10(13)$ & $7(13)$ & $13(13)$ & $7(13)$ & $8(13)$ \\
\hline
\end{tabular}

Table 6. Difference 2-value matrices between To-Be and As-Is matrices (conservative interpretation and inclusive interpretation)

\begin{tabular}{lccccccccc}
\hline Org. Unit & Phase & $\begin{array}{c}\text { Preliminary } \\
\text { project }\end{array}$ & Quotation & Contracting & Project & $\begin{array}{c}\text { Product } \\
\text { plann }\end{array}$ & $\begin{array}{c}\text { Product } \\
\text { launch }\end{array}$ & Production & Testing \\
\hline Marketing \& selling & $0(0)$ & $0(0)$ & $0(0)$ & $1(0)$ & $1(0)$ & $1(0)$ & $1(0)$ & $1(1)$ & $0(0)$ \\
\hline Design commercial & $0(0)$ & $1(0)$ & $1(0)$ & $0(0)$ & $1(0)$ & $1(1)$ & $1(0)$ & $1(0)$ & $0(1)$ \\
\hline Process planning & $1(0)$ & $1(0)$ & $0(1)$ & $1(0)$ & $1(0)$ & $1(1)$ & $1(0)$ & $1(1)$ & $0(1)$ \\
\hline Product planning & $1(1)$ & $0(1)$ & $0(1)$ & $1(1)$ & $0(0)$ & $0(0)$ & $0(0)$ & $0(1)$ & $1(1)$ \\
\hline Purchasing & $1(0)$ & $1(0)$ & $1(1)$ & $1(0)$ & $0(0)$ & $1(1)$ & $0(0)$ & $0(1)$ & $0(1)$ \\
\hline Finance & $1(0)$ & $1(0)$ & $1(0)$ & $1(0)$ & $0(0)$ & $1(0)$ & $1(0)$ & $1(1)$ & $1(1)$ \\
\hline Human resources & $0(0)$ & $0(0)$ & $0(0)$ & $0(0)$ & $1(0)$ & $1(0)$ & $0(0)$ & $1(0)$ & $1(0)$ \\
\hline Logistics & $0(1)$ & $1(1)$ & $1(1)$ & $1(1)$ & $0(0)$ & $0(0)$ & $1(0)$ & $1(1)$ & $0(0)$ \\
\hline Production & $0(1)$ & $0(1)$ & $0(1)$ & $1(1)$ & $1(0)$ & $1(0)$ & $0(0)$ & $1(0)$ & $1(0)$ \\
\hline Maintenance & $0(1)$ & $0(1)$ & $0(1)$ & $0(1)$ & $1(1)$ & $1(1)$ & $0(0)$ & $1(0)$ & $1(0)$ \\
\hline Quality control (Inspection) & $0(1)$ & $0(1)$ & $0(1)$ & $1(1)$ & $1(0)$ & $1(0)$ & $0(0)$ & $0(0)$ & $1(0)$ \\
\hline Laboratory testing & $1(1)$ & $1(1)$ & $1(1)$ & $1(1)$ & $1(1)$ & $1(1)$ & $1(0)$ & $0(0)$ & $1(0)$ \\
\hline Transport & $0(0)$ & $0(1)$ & $0(1)$ & $1(1)$ & $1(1)$ & $1(1)$ & $0(0)$ & $1(0)$ & $0(0)$ \\
\hline Total & $5(6)$ & $6(7)$ & $5(9)$ & $10(7)$ & $9(3)$ & $11(6)$ & $6(0)$ & $9(6)$ & $7(5)$ \\
\hline
\end{tabular}


of the case studies, was calculated and presented in columns 5 and 6 of Table 7.

The highlighted results in columns 5 and 6 of Table 7 are the most important, because they quantitatively reveal the differences in assessment of the simultaneity of processes under different interpretation, which constitutes the base for the research thesis validation. Simultaneity degrees results show variations of:

i) $D_{C E}$ between 9.43 and $148.09 \%$, with a mean of $51.73 \%$;

ii) $W$ between 10.64 and $550.00 \%$ with a mean of $98.56 \%$; and

iii) $w$ between 1.09 and $172.00 \%$, with a mean of $26.97 \%$.

The results clearly demonstrate the superiority of the interpretation-based approach versus a traditional approach. Specifically, depending on the measure applied and the case analyzed, the errors of the assessment might be between 9.43 and $550.00 \%$. If means are considered, the errors might be between 26.97 and $98.56 \%$.

Special attention should be paid to the matrix difference that represents the assessment of the intervention areas in which it would be necessary to act for the CE implementation, and which is actually one of the main objectives of the $\mathrm{CE}$ implementation methodology. Numerically, the results are:

i) $D_{C E}$ between 27.94 and $137.54 \%$ with a mean of $65.54 \%$,

ii) $W$ between 32.20 and $550.00 \%$ with a mean of $178.58 \%$, and

iii) $w$ between 5.75 and $172.00 \%$ with a mean of $61.77 \%$.

The practical importance of these data is exceptionally high, or critical. In practice, it would mean that the $\mathrm{CE}$ implementation managers, applying traditional, and not the pragmatics-based approach, could be faced with large under- or over-estimations. The consequences are well known: challenged or failed projects.

On the basis of the analysis and evidence provided, we can conclude that the main research thesis of the paper has been confirmed, i.e. the interpretations significantly influence the assessment and that, consequently, the communication, negotiation and similar pragmatics instruments, should take place within the CE implementation methodology.

\section{CONCLUSIONS}

We draw a two-pronged conclusion with respect to CE implementation:

Table 7. Simultaneity evaluation and difference in simultaneity evaluation between two interpretations

\begin{tabular}{|c|c|c|c|c|c|c|}
\hline \multirow{3}{*}{ CASE } & \multirow{2}{*}{ Matrix } & \multirow{2}{*}{ Measure } & \multicolumn{2}{|c|}{$\begin{array}{l}\text { Simultaneity } \\
\text { assessment }\end{array}$} & \multicolumn{2}{|c|}{$\begin{array}{l}\text { Difference in simultaneity assessment } \\
\text { between two interpretations }\end{array}$} \\
\hline & & & $\begin{array}{c}\text { Conservative } \\
\text { interpretation } I_{1}\end{array}$ & $\begin{array}{c}\text { Inclusive } \\
\text { interpretation } I_{2}\end{array}$ & in relation to $I_{1}$ & in relation to $I_{2}$ \\
\hline & 1 & 2 & 3 & 4 & $\begin{array}{c}5 \\
(|(3-4)| / 3) \times 100 \%[\%]\end{array}$ & $\begin{array}{c}6 \\
(|(3-4)| / 4) \times 100 \%[\%]\end{array}$ \\
\hline \multirow{9}{*}{$\begin{array}{l}\text { CASE } 1 \\
\text { Company A }\end{array}$} & \multirow[t]{3}{*}{ As-Is } & $D_{C E}$ & 43.94 & 68.18 & 55.17 & 35.55 \\
\hline & & $\Omega$ & 23 & 39 & 69.57 & 41.03 \\
\hline & & $\omega$ & 0.79 & 0.87 & 10.13 & 9.20 \\
\hline & \multirow[t]{3}{*}{ To-Be } & $D_{C E}$ & 72.73 & 80.3 & 10.41 & 9.43 \\
\hline & & $\Omega$ & 42 & 47 & 11.90 & 10.64 \\
\hline & & $\omega$ & 0.88 & 0.89 & 1.14 & 1.12 \\
\hline & \multirow[t]{3}{*}{ Difference } & $D_{C E}$ & 28.79 & 12.12 & 57.90 & 137.54 \\
\hline & & $\Omega$ & 13 & 2 & 84.62 & 550.00 \\
\hline & & $\omega$ & 0.68 & 0.25 & 63.24 & 172.00 \\
\hline \multirow{9}{*}{$\begin{array}{l}\text { CASE } 2 \\
\text { Company B }\end{array}$} & \multirow[t]{3}{*}{ As-Is } & $D_{C E}$ & 23.08 & 57.26 & 148.09 & 59.69 \\
\hline & & $\Omega$ & 18 & 58 & 222.22 & 68.97 \\
\hline & & $\omega$ & 0.67 & 0.87 & 29.85 & 22.99 \\
\hline & \multirow[t]{3}{*}{ To-Be } & $D_{C E}$ & 81.20 & 99.15 & 22.11 & 18.10 \\
\hline & & $\Omega$ & 86 & 107 & 24.42 & 19.63 \\
\hline & & $\omega$ & 0.91 & 0.92 & 1.10 & 1.09 \\
\hline & \multirow[t]{3}{*}{ Difference } & $D_{C E}$ & 58.12 & 41.88 & 27.94 & 38.78 \\
\hline & & $\Omega$ & 59 & 40 & 32.20 & 47.50 \\
\hline & & $\omega$ & 0.87 & 0.82 & 5.75 & 6.10 \\
\hline
\end{tabular}


1. The pragmatics-based approach, which implies evaluation of different interpretations of the data, has been proven to be relevant for the $\mathrm{CE}$ implementation methodology (simultaneity of the processes assessment, and identification of intervention areas for $\mathrm{CE}$ implementation has been addressed). It has been proven that the assessment results are interpretation dependent and, therefore, the application of traditional methodologies may lead to failure or serious challenges of projects. Therefore, it has been demonstrated that application of a pragmaticsbased approach might significantly improve the potential for the successful implementation of $\mathrm{CE}$, which leads towards validation of the primary research thesis of the relevance of the pragmaticsbased approach for $\mathrm{CE}$ implementation methodology.

2. The case studies demonstrate the utility and effectiveness of the applied methodology which, although simple, exhibits the sensitivity and capability of identification of phenomenologically highly salient features of the company organization in terms of the CE paradigm. The proposed methodology, with a higher level of certainty than the traditional approaches, clearly identifies areas of primary attention and needs for intervention in the company of concern. The case studies also demonstrated the simplicity of the methodology, which also implies its efficiency, which is one of the business requirements for this stage of evaluation of strategy applied in the companies.

Recommendations for future research are as follows:

1. to investigate additional types of interpretations and their applications;

2. to further improve the methodology and to develop a computer-based tool for its application;

3. to assure better perception of the existing measures implications, to improve their definitions, as well as to develop a new, superior, set of measures;

4. the pragmatics-based approach should be applied to other methodologies, particularly the RACEbased methodologies, i.e. to embed an analysis of different possible interpretations of the evaluation of different factors of the $\mathrm{CE}$ readiness assessments as well as on the evaluation of the results achieved, and further to apply the pragmatics-based approach throughout the $\mathrm{CE}$ implementation methodologies. In other words, the traditional methodologies should be upgraded with the pragmatics perspective

Finally,

1. pragmatics might be considered within the $\mathrm{CE}$ practice itself, not only within the $\mathrm{CE}$ implementation;

2. application of a pragmatics-based approach means, in fact, the implementation of the concept of co-design, co-creation, co-development (see [16] and [17]), which is fully in accordance with the paradigm of communication as an instrument for organization building, especially as co-design, co-creation, co-development are inherent for $\mathrm{CE}$ as it is paradigmatically based on teamwork (e.g. see [7]);

3. the experiments presented demonstrate the importance of the emergent manufacturing systems, such as Ubiquitous Manufacturing Systems (UMS) [2] with embedded (human) communication functionalities as a regular instrument permanently available for manufacturing system organization creation, i.e. co-creation.

\section{ACRONYMS}

CE Concurrent Engineering

CERA Concurrent Engineering Readiness Assessment

NPD New Product Development

SCM Simultaneity (Concurrency) Matrix

\section{ACKNOWLEDGEMENTS}

The authors wish to acknowledge for providing support and assistance in performing research and data gathering: the Foundation for Science and Technology - FCT, Project PTDC/EME-GIN/102143/2008, Ubiquitous-oriented embedded systems for globally distributed factories of manufacturing enterprises, and EUREKA, Project E! 4177-Pro-Factory UES.

\section{REFERENCES}

[1] Putnik, G.D. (2010), Semiotics-based manufacturing system integration. International Journal of Computer Integrated Manufacturing, vol. 23, no. 8-9, p. 687-690, DOI:10.1080/0951192X.2010.513809.

[2] Putnik, G.D., Putnik, Z. (2010), A semiotic framework for manufacturing systems integration - Part I: Generative integration model. International Journal of Computer Integrated Manufacturing, vol. 23, no. 8-9, p. 691-709, DOI:10.1080/0951192X.2010.510292. 
[3] The Standish Group Int. (2005). Chaos Rising: A Chaos Executive Commentary, Report. The Standish Group Int., West Yarmouth.

[4] Putnik, G.D., Lima, M., Lima, P. (2002). Implementing and improving the concurrent engineering applications: the case of a mould making company. Proceedings of the 18th International Conference on CAD/CAM, Robotics and Factories of the Future, Porto, p. 117125.

[5] Morris, C. (1971). Writtings on the General Theory of Signs. Mouton, Hague, Paris.

[6] Winner, R.I., Pennell, J.P., Bertrand, H.E., Slusarzuk, M.M.G. (1988). The Role of Concurrent Engineering in Weapon Systems Acquisition. Institute of Defense Analyses Report R-338, Alexandria.

[7] Rihar, L., Kušar, J., Gorenc, S., Starbek, M. (2012). Teamwork in the simultaneous product realisation, Strojniški vestnik - Journal of Mechanical Engineering, vol. 58 no. 9, p. 534-544.

[8] Yassine, A.A., Chelst, K.R., Falkenburg, D.R. (1999). A decision analytic framework for evaluating concurrent engineering. IEEE Transactions on Engineering Management, vol. 46, no. 2, p. 144-157, DOI:10.1109/17.759142.

[9] Hartley, J.R. (1992). Concurrent Engineering: Shortening Lead Times, Raising Quality and Lowering Costs. Productivity Press, Cambridge.

[10] Karandikar, H.M., Fotta, M.E., Lawson, M., Wood, R.T. (1993). Assessing organizational readiness for implementing concurrent engineering practices and collaborative technologies. Proceedings of the $2^{\text {nd }}$ Workshop on Enabling Technologies: Infrastructure for Collaborative Enterprises, Los Alamitos, p. 83-93.
[11] Khalfan, M.M.A., Anumba, C.J., Siemieniuch, C.E., Sinclair, M.A. (2001). Readiness Assessment of the construction supply chain for concurrent engineering. European Journal of Purchasing \& Supply Management, vol. 7, no. 2, p. 141-153, DOI:10.1016/ S0969-7012(00)00023-X.

[12] Villa, C., Romero, F., Contero, M. (2004). Implementing collaborative engineering environments through reference model-based assessment, Luo, Y. (ed.): Cooperative Design, Visualisation, and Engineering, Springer, Berlin. Heidelberg, p. 79-86.

[13] Žargi, U., Kušar, J., Berlec, T., Starbek, M. (2009). A company's readiness for concurrent product and process development. Strojniški vestnik - Journal of Mechanical Engineering, vol. 55, no. 7-8, p. 427-437.

[14] Haberle, K.R., Burke, R.J., Graves, R.J. (2000). A note on measuring parallelism in concurrent engineering. International Journal of Production Research, vol. 38, no. 8, p 1947-1952, DOI:10.1080/002075400188672.

[15] Goldense, B.L. (1994). Predictive metrics for concurrent engineering. Electro International Conference Proceedings. Combined Volumes. Boston, p. 485-504.

[16] Ueda, K., Markus, A. Monostori, L., Kals H.J.J., Arai, T. (2001). Emergent synthesis methodologies for manufacturing original research article. CIRP Annals Manufacturing Technology, vol. 50, no. 2, p. 535-551.

[17] Kito, T., Fujii, N., Ueda, K. (2004). Co-creative decision making in artifactual systems in consideration of bounded rationality. Proccedings of EES: Experiments in Economic Sciences - New Approaches to Solving Real-world Problems, p. 303-317. 